\title{
Adverse events during reoperative cardiac surgery: Frequency, characterization, and rescue
}

\author{
Eric E. Roselli, MD, ${ }^{a}$ Gösta B. Pettersson, MD, PhD, ${ }^{a, *}$ Eugene H. Blackstone, MD, ${ }^{a, b, \dagger}$ Mariano E. Brizzio, MD, ${ }^{a}$ \\ Penny L. Houghtaling, MS, ${ }^{\text {b }}$ Regina Hauck, MBA, ${ }^{a}$ Jacob M. Burke, ${ }^{a}$ and Bruce W. Lytle, MD ${ }^{a}$
}

Earn CME credits at http:// cme.ctsnetjournals.org

丹 Supplemental material is available online.
From the Departments of Thoracic and Cardiovascular Surgery a and Quantitative Health Sciences, ${ }^{\mathrm{b}}$ Cleveland Clinic, Cleveland, Ohio.

Read at the Eighty-seventh Annual Meeting of The American Association for Thoracic Surgery, Washington, DC, May 5-9, 2007.

* Supported in part by the Peter and Elizabeth C. Tower and Family Endowed Chair in Cardiothoracic Research.

${ }^{\dagger}$ Supported in part by the Kenneth Gee and Paula Shaw, PhD, Chair in Heart Research.

Received for publication May 4, 2007; revisions received Aug 13, 2007; accepted for publication Aug 23, 2007.

Address for reprints: Eric E. Roselli, MD, Department of Thoracic and Cardiovascular Surgery, Cleveland Clinic, 9500 Euclid Ave/Desk F24, Cleveland, OH 44195 (E-mail: roselle@ccf.org).

J Thorac Cardiovasc Surg 2008;135:316-23 0022-5223/\$34.00

Copyright $\odot 2008$ by The American Association for Thoracic Surgery

doi:10.1016/j.jtcvs.2007.08.060
Objectives: To (1) determine frequency of occurrence and risk factors for intraoperative adverse events (IAE) during reoperative cardiac surgery, (2) characterize them with respect to structure injured, timing, and use of preventive strategies, and (3) identify the impact on outcome in terms of successful and unsuccessful rescue and cost.

Methods: Operative notes of 1847 patients undergoing reoperative cardiac surgery were reviewed to identify and characterize documented intraoperative adverse events. Logistic regression modeling was used to identify risk factors for intraoperative adverse events and outcomes. Expected versus observed poor outcomes (stroke, myocardial infarction, death) was used to measure rescue.

Results: Among 127 patients, $145(7 \%)$ intraoperative adverse events occurred. These included injuries to bypass grafts $(n=47)$, heart $(n=38)$, and great vessels $(n=28)$ and ischemia without graft injury $(n=22)$. Most occurred on opening $(n=34,23 \%)$ and during prebypass dissection $(\mathrm{n}=57,39 \%)$. Risk incremented as reoperations increased. Seventy-seven patients experienced 1 or more lapses in preventive strategies. Patients with intraoperative adverse events had a greater number of poor outcomes $(\mathrm{n}=24[19 \%]$ vs $\mathrm{n}=107$ [6.2\%]; $P<.0001)$ and incurred higher direct technical intraoperative and postoperative costs (ratio 1.3). Twelve patients with intraoperative adverse events were predicted to have poor outcomes versus 24 who did $(P<.0001)$, indicating 12 "failures to rescue."

Conclusions: Adverse events still occur regularly during cardiac reoperation, are related to complexity of the procedure, and occur particularly during dissection and often when preventive strategies have not been used. Compensatory rescue measures are not always successful. Adverse events lead to poor patient outcome and higher cost.

$\mathrm{M}$ ishaps still regularly occur during cardiac reoperations. Most of these events can be anticipated, and they occur despite utmost efforts to avoid them. Recently, it has been shown that reoperation per se in select groups of patients no longer appears to be a major risk factor for poor outcome. ${ }^{1,2}$ This seems in part related to the implementation of strategies to prevent mishaps and to compensate for them when they occur to avoid poor patient outcome.

Purposes of this study were to (1) determine frequency of occurrence of reported intraoperative adverse events (IAE) and their risk factors, (2) characterize them with respect to structure injured, timing of their occurrence, and lapses of preventive strategies, and (3) identify the impact on outcome in terms of successful and unsuccessful rescue and cost.

\section{Patients and Methods \\ Patients}

Between July 2002 and July 2004, 1985 consecutive cardiac reoperations were performed at Cleveland Clinic; 65 patients undergoing heart transplantation and 73 with repairs of the descending aorta via thoracotomy were excluded, leaving 1819 who underwent 1847 reoperations. During the subsequent 18 months, July 2004 to January 2006, prospective IAE data 

Abbreviations and Acronyms
$\mathrm{CPB}=$ cardiopulmonary bypass
$\mathrm{CL}=$ confidence limits
$\mathrm{CT}=$ computed tomography
IAE $=$ intraoperative adverse event
ITA $=$ internal thoracic artery
MRI $=$ magnetic resonance imaging
$\mathrm{SD}=$ standard deviation

were recorded on 245 patients undergoing reoperation by one surgeon (G.B.P.) to validate reporting of events.

\section{Data Collection}

Operative notes were reviewed to identify recorded IAEs. A data collection tool was created to capture perioperative details (Appendix E1) not gathered prospectively for the Cardiovascular Information Registry. For each IAE, conditional statements were used to determine whether imaging, circulatory support, or technical preventive strategies had been used (Appendix E2).

The Institutional Review Board of the Cleveland Clinic approved use of these data and databases for research.

\section{Characterization of IAEs}

IAEs were categorized on the basis of (1) injured structures, (2) timing of the IAE during surgery, and (3) lapse of preventive strategies. A more elaborate description of reoperative strategies and surgical challenges is presented in Appendix E3.

Injured structures included those to bypass grafts, heart, great vessels, and other (new intraoperative ischemia not associated with direct injury and documented by electrocardiographic changes, ventricular fibrillation, or bradycardia requiring change in surgical progress, as well as severe lung injury).

Lapses in preventive strategies attributed to imaging included the following:

- Injury to bypass grafts, native coronary vessels, right ventricle, or brachiocephalic vein on opening when the patient did not have preoperative computed tomography (CT) or magnetic resonance imaging (MRI)

- Internal thoracic artery (ITA) or vein graft injury when it was immobile on preoperative angiography

- Requirement for additional revascularization without preoperative mapping of conduit availability

Lapses attributed to circulatory support because extrathoracic cannulation site was not exposed or used included the following:

- Injury on opening despite a preoperative cardiac catheterization, CT, or MRI identifying structure at immediate risk

- Injury to an ITA crossing the midline or to an immobile graft

Lapses attributed to surgical technique included the following:

- Injury during sternotomy after wires removed

- Failure to first mobilize the right sternal border and injury requiring cannulation occurred

- Tearing of right ventricle or atrium caused by traction

- Ventricular fibrillation triggered by cautery

- Ischemia triggered by manipulating or cauterizing vein graft or arteriosclerotic aorta
Patient outcome. Poor outcome was the composite end point of stroke, myocardial infarction, or hospital death as defined for The Society of Thoracic Surgeons national database. (For details, see http://www.ctsnet.org/file/rptDataSpecifications252_1_For VendorsPGS.pdf.)

Rescue and failure to rescue. Once injury or ischemia occurs, primary objectives of a rescue strategy are to establish and maintain perfusion to protect brain and heart. Efficiency of compensatory strategies to accomplish this was assessed by ability to prevent stroke, myocardial infarction, and death.

Cost. Detailed operative and postoperative direct technical costs were extracted for each patient from the hospital's cost-accounting system. Direct technical costs included anesthesia, surgery, pathology, nursing (operating room, intensive care unit, hospital, rehabilitation), pharmacy, respiratory therapy, radiology, laboratory, pain management, and miscellaneous. (For details, see http://www.eclipsys.com/ Solutions/executives.asp). Indirect costs and professional fees were not included.

\section{Data Analysis}

Categorical variables are summarized by frequencies and percentages and continuous variables by means \pm 1 standard deviation. Group comparisons were made with the $\chi^{2}$ or Wilcoxon rank sum tests.

Risk factors. Risk factors associated with IAEs and with poor outcomes (stroke, myocardial infarction, hospital death) in all patients and in the subset of patients with IAEs were identified by bootstrap bagging ${ }^{3,4}$ using the variables listed in Appendix E4, with automated stepwise analysis of 1000 bootstrap resamplings and a $P$ value for variable retention of .05 . Thereafter, these analyses were aggregated and variables or closely correlated clusters of variables appearing in $50 \%$ of analyses or more were retained in the final multivariable model.

Rescue and failure to rescue. To determine whether poor outcomes were more common in the IAE group, we used logistic regression analysis to model the composite end point occurring in the non-IAE group (Appendix E5). Variable selection used bagging, with resampling of 1000 bootstrap samples and retention of variables $P<.05$. The resulting model was used to predict expected number of events in the IAE group. This was compared with number of observed events by a $\chi^{2}$ test. The difference between expected and observed poor outcomes was designated "failure to rescue."

Risk factors found were only univariably evaluated in the IAE group, because a reliable, robust multivariable model could not be formed with so few events ( $\mathrm{n}=24$ in the IAE group).

Cost. The unadjusted direct technical cost ratio of IAE and the non-IAE groups was calculated from median cost. To make a fair comparison, we developed a propensity model ${ }^{5,6}$ by augmenting the logistic regression model of predictors for IAE with other preoperative and intraoperative factors (Appendix E4). This propensity model was used to compute a propensity score for each patient, and the scores were used to obtain pairs of matched patients from the two groups. Distribution of median cost ratios from 10,000 bootstrap runs of the matched pairs was evaluated to approximate the adjusted cost ratio and provide confidence intervals around the estimate.

Presentation. Mean values are accompanied by \pm 1 standard deviation (SD) and regression coefficients by \pm 1 standard error. Proportions are accompanied by $68 \%$ confidence limits (CL, equivalent 
TABLE 1. Characteristics of patients with and without IAEs

\begin{tabular}{|c|c|c|c|}
\hline \multirow[b]{2}{*}{ Characteristic } & \multirow{2}{*}{$\frac{\text { Total }=1847}{\text { No. }(\% \text { of total) }}$} & \multicolumn{2}{|c|}{$\operatorname{IAE}(n=127)$} \\
\hline & & No. $(\%)$ & $P$ value \\
\hline \multicolumn{4}{|l|}{ Demography } \\
\hline Female & $562(30)$ & $40(7.1)$ & \\
\hline Age $(y)$, mean $\pm S D$ & $65 \pm 13$ & $\begin{array}{c}67 \pm 13, \text { IAE } \\
65 \pm 13, \text { no IAE }\end{array}$ & .04 \\
\hline \multicolumn{4}{|l|}{ Cardiac history/indications } \\
\hline Reoperation number & & & .14 \\
\hline 1 & $1454(79)$ & $92(6.3)$ & \\
\hline 2 & $327(18)$ & $28(8.6)$ & \\
\hline 3 & $58(3.1)$ & $5(8.6)$ & \\
\hline 4 or more & $8(0.4)$ & $2(25)$ & \\
\hline NYHA class & & & .5 \\
\hline Emergency/urgent operation & & & .3 \\
\hline No & $1804(98)$ & $126(6.9)$ & \\
\hline Yes & $43(2.3)$ & $1(2.3)$ & \\
\hline Coronary artery disease* & & & .03 \\
\hline 0 & $409(25)$ & $20(4.9)$ & \\
\hline 1 & $155(9.5)$ & $9(5.8)$ & \\
\hline 2 & $270(17)$ & $15(5.6)$ & \\
\hline 3 & $802(49)$ & $73(9.1)$ & \\
\hline No coronary angiogram & 211 & 10 & \\
\hline Previous MI & & & .6 \\
\hline No & $879(48)$ & $58(6.6)$ & \\
\hline Ejection fraction $(\%)$, mean $\pm S D$ & $46 \pm 13$ & $\begin{array}{c}46 \pm 13, \text { IAE } \\
46 \pm 13, \text { no IAE }\end{array}$ & .9 \\
\hline Endocarditis & & & .8 \\
\hline No & $1685(91)$ & $115(6.8)$ & \\
\hline Yes & $162(8.8)$ & $12(7.4)$ & \\
\hline $\begin{array}{l}\text { Time to reoperation (y), median } \\
\text { (15th, 85th percentiles) }\end{array}$ & $8.6(1.1,18)$ & $\begin{array}{c}8.8(2.6,18), \text { IAE } \\
8.6(1.1,18), \text { no IAE }\end{array}$ & .5 \\
\hline \multicolumn{4}{|l|}{ Noncardiac comorbidity } \\
\hline History of chest radiation & & & .005 \\
\hline No & $1470(98)$ & $96(6.5)$ & \\
\hline Yes & $25(1.7)$ & $6(24)$ & \\
\hline Smoking & & & .4 \\
\hline No & $727(40)$ & $55(7.6)$ & \\
\hline Yes & $1115(60)$ & $72(6.5)$ & \\
\hline COPD & & & .5 \\
\hline No & $1358(74)$ & $97(7.1)$ & \\
\hline Yes & $489(26)$ & $30(6.1)$ & \\
\hline
\end{tabular}


TABLE 1. Continued

\begin{tabular}{|c|c|c|c|}
\hline \multirow[b]{2}{*}{ Characteristic } & \multirow{2}{*}{$\frac{\text { Total }=1847}{\text { No. }(\% \text { of total) }}$} & \multicolumn{2}{|c|}{$\operatorname{IAE}(n=127)$} \\
\hline & & No. $(\%)$ & $P$ value \\
\hline PAD & & & .003 \\
\hline No & $817(44)$ & $40(4.9)$ & \\
\hline Yes & $1,030(56)$ & $87(8.5)$ & \\
\hline Diabetes & & & .4 \\
\hline No & $1406(76)$ & $101(7.2)$ & \\
\hline Yes & $441(24)$ & $26(5.9)$ & \\
\hline Hypertension & & & .10 \\
\hline No & $475(26)$ & $25(5.3)$ & \\
\hline Yes & $1366(74)$ & $102(7.5)$ & \\
\hline Renal failure & & & .5 \\
\hline No & $1698(92)$ & $119(7.0)$ & \\
\hline Yes & $149(8.0)$ & $8(5.4)$ & \\
\hline Carotid disease & & & .003 \\
\hline No & $876(48)$ & $44(5.0)$ & \\
\hline Yes & $971(52)$ & $83(8.5)$ & \\
\hline Arteriosclerotic aorta & & & .09 \\
\hline No & $1560(85)$ & $114(7.3)$ & \\
\hline Yes & $287(15)$ & $13(4.5)$ & \\
\hline \multicolumn{4}{|c|}{ Previous cardiac operations } \\
\hline \multicolumn{4}{|c|}{ Valve repair or replacement } \\
\hline Aortic & & & .99 \\
\hline No & $1439(78)$ & $99(6.9)$ & \\
\hline Yes & $408(22)$ & $28(6.9)$ & \\
\hline Mitral & & & .01 \\
\hline No & $1490(810)$ & $113(7.6)$ & \\
\hline Yes & $357(19)$ & $14(3.9)$ & \\
\hline Tricuspid & & & .2 \\
\hline No & $1799(97)$ & $126(7.0)$ & \\
\hline Yes & $48(2.6)$ & $1(2.1)$ & \\
\hline CABG & & & .002 \\
\hline No & $656(36)$ & $29(4.4)$ & \\
\hline Yes & $1191(64)$ & $98(8.2)$ & \\
\hline ITA grafting & & & .003 \\
\hline No & $1005(54)$ & $53(5.3)$ & \\
\hline Yes & $842(46)$ & $74(8.8)$ & \\
\hline Thoracic aorta repair & & & .6 \\
\hline No & $1742(94)$ & $121(6.9)$ & \\
\hline Yes & $105(5.7)$ & $6(5.7)$ & \\
\hline Place of operation & & & .5 \\
\hline CCF & $537(29)$ & $34(6.3)$ & \\
\hline Elsewhere & $1310(71)$ & $93(7.1)$ & \\
\hline
\end{tabular}

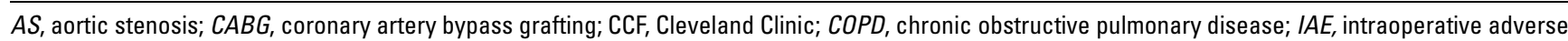
event; ITA, internal thoracic artery; $M I$, myocardial infarction; $M R$, mitral regurgitation; NYHA, New York Heart Association; PAD, peripheral arterial disease; $S D$, standard deviation. ${ }^{*}$ Number of systems with $\geq 50 \%$ stenosis.

to \pm 1 standard error). Logistic regression results were not presented as odds ratios because of data transformations.

\section{Results}

Frequency of Occurrence of IAEs and Risk Factors

A total of 145 IAEs occurred in 127 patients (7\% of the 1847 reoperations). There were few preoperative differences between patients experiencing an IAE and those who did not
(Table 1). Risk factors for occurrence of IAEs included increasing number of reoperations and history of chest radiation (Table 2). Type or place of previous operation was not reliably identified as a risk factor for occurrence of IAEs.

\section{Characterization of Intraoperative Adverse Events}

Structure injured. Category of injured structure is described in Table 3. Severe bleeding was the immediate 
TABLE 2. Incremental risk factors for IAEs

\begin{tabular}{|c|c|c|c|}
\hline Factor & Estimate \pm SE & $P$ value & Reliability (\%)* \\
\hline Reoperation number & $0.37 \pm 0.15$ & .012 & 62 \\
\hline History of chest radiation & $1.6 \pm 0.48$ & .0014 & 76 \\
\hline Lower preoperative bilirubin $\dagger$ & $-0.41 \pm 0.16$ & .013 & 50 \\
\hline Intercept & $-3.7 \pm 0.38$ & $<.0001$ & - \\
\hline
\end{tabular}

$I A E$, Intraoperative adverse event; $S E$, standard error. C-statistic $=0.66$. *Percent of times factor appeared in 1000 bootstrap analyses. †Logarithmic transformation.

manifestation of the event in 65 (arterial in 46, venous in 19), ischemia in 40 , arrhythmia in 9 , and lung injury in 5 . Severe lung injuries occurred during pre-pump dissection and were associated with severe bleeding $(n=1)$ or air leak $(n=4)$ to an extent requiring change of operative strategy: chest closure and intensive care unit resuscitation $(\mathrm{n}=2)$, placing a bronchial blocker $(n=1)$, early initiation of cardiopulmonary bypass $(\mathrm{CPB})(\mathrm{n}=1)$, and abandoning an attempted right thoracotomy approach in favor of high-risk sternotomy $(\mathrm{n}=1)$. All these patients had moderate-to-severe emphysema, and all operations were eventually completed. Exposure, repair, and consequences of omitting retrograde cardioplegia after coronary sinus injuries are more problematic in the reoperative setting. Coronary sinus injuries were caused by retrograde cannula insertion or cardioplegia infusion in all but 1 patient, who had a mitral anuloplasty stitch catching the cannula; subsequent cannula removal resulted in injury.

Timing. The majority of the events occurred during dissection before aortic clamping; only $23 \%$ occurred during resternotomy (Table 3).

Lapses in preventive strategies. One or more preventive strategy lapses occurred in 77 (55\%) of the 127 patients experiencing IAEs (Table 4). Most were due to incomplete preoperative imaging. Technical strategy violations included 7 injuries on opening after sternal wires were pulled, and another 10 injuries were attributed by the surgeon to technique, including improper use of electrocautery $(n=2)$, excessive retraction $(n=3)$, and violation of "no touch" principles when dealing with diseased bypass grafts $(n=5)$.

Validation. In the validation cohort of 245 patients, 19 (7.8\%) patients experienced 21 IAEs similar in characteristics and timing to those in the study group (Table 3 ).

\section{Patient Outcome}

A total of 84 patients died in hospital after the 1847 reoperations (4.5\%), 15 in the IAE group (12\%, 68\% CL 8.9\%-15\%) and 69 in the non-IAE group $(4.0 \%, 68 \%$ CL $3.5 \%-4.5 \%)$, $P<.0001$. Risk factors for poor outcome included the occurrence of IAEs and multiple IAEs (Table 5).

Among the 127 patients with IAEs, 24 (19\%) experienced 1 or more poor outcomes: stroke (8), myocardial infarction (5), or death (15). The 16 patients who had more than 1 IAE had
TABLE 3. Characterization of structure injured and associated poor outcomes

\begin{tabular}{|c|c|c|c|}
\hline $\begin{array}{l}\text { Intraoperative } \\
\text { adverse event }\end{array}$ & $\begin{array}{c}\text { No. } \\
(\% \text { of } 145)\end{array}$ & $\begin{array}{c}\text { Poor outcome, } \\
\text { No. }(\%)\end{array}$ & $\begin{array}{c}\text { Validation cohort, } \\
\text { No. }(\% \text { of } 21)\end{array}$ \\
\hline $\begin{array}{c}\text { Injury to bypass } \\
\text { grafts }\end{array}$ & 47 (32) & $9(19)$ & $4(19)$ \\
\hline ITA & 25 & $3(12)$ & \\
\hline Saphenous vein & 21 & $6(28)$ & 3 \\
\hline Arterial graft & 1 & $0(0)$ & 1 \\
\hline Injury to heart & $38(26)$ & $8(21)$ & $6(29)$ \\
\hline Right ventricle & 7 & $2(28)$ & \\
\hline Right atrium & 12 & $1(8.3)$ & 3 \\
\hline Left ventricle & 6 & $1(17)$ & \\
\hline $\begin{array}{l}\text { Left atrium } \\
\text { or pulmonary } \\
\text { veins }\end{array}$ & 2 & $0(0)$ & \\
\hline $\begin{array}{l}\text { Native coronary } \\
\text { artery }\end{array}$ & 7 & $2(28)$ & 1 \\
\hline Coronary sinus & 4 & $2(50)$ & 2 \\
\hline $\begin{array}{c}\text { Injury to great } \\
\text { vessels }\end{array}$ & $28(19)$ & $4(14)$ & $7(33)$ \\
\hline Aorta & 13 & $3(23)$ & 2 \\
\hline Pulmonary artery & 7 & $1(14)$ & 2 \\
\hline $\begin{array}{l}\text { Brachiocephalic } \\
\text { vein }\end{array}$ & 8 & $0(0)$ & 3 \\
\hline Other & $32(22)$ & $8(25)$ & 4 (19) \\
\hline New ischemia & 22 & $6(27)$ & 2 \\
\hline Bradycardia & & & 1 \\
\hline $\begin{array}{l}\text { Ventricular } \\
\text { fibrillation }\end{array}$ & 5 & $2(40)$ & \\
\hline Lung injury & 5 & $0(0)$ & 1 \\
\hline $\begin{array}{c}\text { Timing of adverse } \\
\text { event }\end{array}$ & & & \\
\hline Opening & $34(23)$ & $5(15)$ & $7(33)$ \\
\hline $\begin{array}{l}\text { Pre-pump } \\
\text { dissection }\end{array}$ & 57 (39) & $10(17)$ & $7(33)$ \\
\hline On CPB & $34(23)$ & $8(23)$ & $4(19)$ \\
\hline $\begin{array}{l}\text { During aortic } \\
\text { clamping }\end{array}$ & $8(6)$ & $1(12)$ & $2(9.5)$ \\
\hline Closing & $12(8)$ & $4(33)$ & $1(4.8)$ \\
\hline
\end{tabular}

CPB, Cardiopulmonary bypass; ITA, internal thoracic artery.

more poor outcomes $(31 \%)$ than those with 1 IAE $(17 \%)$, $P<.0001$. Return to the operating room for bleeding was similar in the IAE and non-IAE groups $(\mathrm{n}=10 / 7.9 \%$ vs $\mathrm{n}=92 /$ $5.3 \% ; P=.2$ ), but patients with IAEs were more likely to have a blood transfusion (IAE group, $\mathrm{n}=78 / 61 \%$ vs non-IAE, $\mathrm{n}=$ $772 / 45 \% ; P=.0003)$. There was no correlation between specific type or timing of IAE with poor outcome (Table 3 ). Patients without lapses $(n=50)$ in preventive strategies had a higher number of poor outcomes than those with such lapses $(\mathrm{n}=77)$ (28\% vs $13 \%$, respectively; $P=.04)$.

Among 1720 non-IAE patients, 107 (6.2\%) experienced 1 or more poor outcomes: stroke (40), myocardial infarction (5), or death (69). 
TABLE 4. Lapses and violations of preventive strategies for intraoperative adverse events and associated outcome

\begin{tabular}{|c|c|c|c|}
\hline Lapse & n & $\begin{array}{l}\text { Hospital death, } \\
\text { No. }(\%)\end{array}$ & $\begin{array}{l}\text { Composite poor } \\
\text { outcome, No. (\%) }\end{array}$ \\
\hline Imaging* & & $P=.07$ & $P=.07$ \\
\hline Yes & 53 & $3(5.7)$ & $6(11)$ \\
\hline No & 74 & $12(16)$ & $18(24)$ \\
\hline Circulatory support* & & $P=.4$ & $P=.5$ \\
\hline Yes & 27 & $2(7.4)$ & $4(15)$ \\
\hline No & 100 & $13(13)$ & $20(20)$ \\
\hline Technical* & & $P=.7$ & $P=.5$ \\
\hline Yes & 17 & $1(5.9)$ & $2(12)$ \\
\hline No & 110 & $14(13)$ & $22(20)$ \\
\hline Total patients & & $P=.08$ & $P=.04$ \\
\hline Yes & 77 & $6(7.8)$ & $10(13)$ \\
\hline No & 50 & $9(18)$ & $14(28)$ \\
\hline
\end{tabular}

*Not mutually exclusive.

Rescue and failure to rescue. Of the 127 patients who had IAEs, 103 were rescued with good outcome. Expected number of poor outcomes in the group of patients experiencing IAEs was $12(9 \%)$, less than the observed number of $24(19 \%)(P<.0001)$. This difference between expected and actual poor outcomes $(\mathrm{n}=12)$ represents "failure to rescue," corresponding to $0.65 \%$ of the total reoperations.

Cost. Unadjusted median direct technical cost was 1.4 times greater for those experiencing an IAE than for those

TABLE 5. Incremental risk factors for poor outcomes (stroke, myocardial infarction, hospital death) in all patients $(\mathrm{n}=1847)$

\begin{tabular}{|c|c|c|c|}
\hline Variable & Estimate \pm SE & $P$ value & $\begin{array}{c}\text { Reliability } \\
(\%)^{*}\end{array}$ \\
\hline \multicolumn{4}{|l|}{$I A E$} \\
\hline $1 \mathrm{IAE}$ & $1.04 \pm 0.28$ & .0002 & 98 \\
\hline$>1 \mathrm{IAE}$ & $2.06 \pm 0.56$ & .0002 & 98 \\
\hline \multicolumn{4}{|l|}{ Prior operation } \\
\hline Prior CABG & $0.88 \pm 0.23$ & $<.0001$ & 70 \\
\hline Prior TV surgery & $1.15 \pm 0.41$ & .005 & 50 \\
\hline \multicolumn{4}{|l|}{ Noncardiac comorbidity } \\
\hline $\begin{array}{l}\text { Higher preoperative } \\
\text { bilirubin } \dagger\end{array}$ & $0.49 \pm 0.15$ & .001 & 86 \\
\hline \multicolumn{4}{|l|}{ Reoperation procedure } \\
\hline $\begin{array}{l}\text { Venous cannulation } \\
\text { right atrium }\end{array}$ & $-0.76 \pm 0.22$ & .0006 & 50 \\
\hline Aortic arterial cannulation & $-0.57 \pm 0.22$ & .009 & 70 \\
\hline AV allograft replacement & $0.97 \pm 0.34$ & .004 & 55 \\
\hline Intercept & $-2.6 \pm 0.26$ & $<.0001$ & - \\
\hline
\end{tabular}

$A V$, Aortic valve; $C A B G$, coronary artery bypass grafting; $I A E$, intraoperative adverse events; $S E$, standard error; $T V$, tricuspid valve. C-statistic $=0.72$. *Percent of times factor appeared in 1000 bootstrap analyses. †Logarithmic transformation. who did not. In the propensity analysis of 118 matched pairs, median cost ratio was 1.3 (68\% CI 1.16-1.4).

\section{Discussion}

As confirmed by this study, reoperation-specific IAEs still occur and clearly contribute to morbidity and mortality. Applying lessons learned from other high-hazard industries to the technically demanding, highly complex task of reoperative cardiac surgery is complicated. Triggered by a series of bad outcomes after neonatal arterial switch operations, de Leval and colleagues ${ }^{7}$ applied Reason's model ${ }^{8}$ of organizational accident causation to study the role of human factors on outcomes after neonatal arterial switch operations across the United Kingdom. They highlighted the role of human as "hazard," responsible for error, versus "hero," able to compensate, adjust, and recover. Applying such an approach to improving safety of reoperative cardiac surgery has not been done, but this study begins this, by presenting a detailed analysis of recorded IAEs.

\section{Principal Findings}

Frequency of occurrence of IAEs and risk factors. These life-threatening major events were uncommon, but still occurred more than once per week during the study period. Literature examining IAEs during reoperative surgery has focused on specific times or sites of injury, such as catastrophic hemorrhage during sternal re-entry or injury to the ITA. ${ }^{9,10}$ Gillinov and colleagues ${ }^{10}$ found ITA injury occurred at a frequency of 5.3\% in 655 patients over a 10 -year period ending in 1996. Improvements in preoperative imaging and planning since then have reduced occurrence of ITA injury to $3 \%$ in the current study.

Patients with multiple previous operations or chest radiation have more severe adhesions, accounting for increased risk of injury seen in the current study. The paucity of other risk factors, such as patent grafts, may actually reflect a heightened awareness of patients and structures at risk and adequate use of preventive strategies.

\section{Characterization of intraoperative adverse event.}

STructure inJured. Although bypass grafts were the structure most commonly recognized as injured, types of IAEs varied widely, including injury to all the mediastinal structures, lungs, and ischemia without direct injury.

TImING. Contrary to popular belief, IAEs occurred during all phases of cardiac reoperations and more commonly after sternal reentry than during. It is likely that the historic increased frequency and catastrophic results of injuries occurring on opening suppressed the relevance of injuries occurring later during the course of the operation, which we have described here. ${ }^{9}$

LAPSES AND VIOLATIONS OF PREVENTIVE STRATEGIES. Most lapses in preventive strategy were related to lack of adequate preoperative imaging. Morashita and colleagues ${ }^{11}$ demonstrated that the safety of third and fourth sternotomies for 
valve surgery can be improved with preoperative CT scans. Coronary angiography and cross-sectional imaging are specifically interpreted to localize and assess mobility of patent grafts. Patent ITAs, including those crossing the midline, are given particular consideration for risk of injury and for preparation of a rescue plan. Immobility of the heart on catheterization is a sign that graft or other structures are embedded in scar tissue, fixed to the chest wall, and in danger of injury. Identifying such a perilous situation should trigger preventive strategies to minimize risk.

Although we were unable to demonstrate a difference between those having their initial operations at our institution versus elsewhere, it is empirically clear that the best way to prevent injury to a patent ITA graft is to position it properly at the original operation. Furthermore, a right coronary graft should not rest over the right ventricle. These two preventive measures are examples of eliminating latent conditions that put patients at future risk.

Obviously, preventive strategies are not always effective, and IAEs are difficult to eliminate. Patients who experienced IAEs without lapses in preventive strategies had worse outcomes than those whose IAEs were associated with such lapses. Likely, preventive strategies were most rigorously used in the perceived highest risk cases. Also, outcome once an IAE has occurred is decided by the success of the employed compensatory strategy.

Patient outcomes. IAEs occurring during reoperative surgery have incurred mortality as high as $37 \%{ }^{12}$ for injuries occurring during sternal reentry and mortality ranging from $9 \%$ to $50 \%$ for injury to a patent ITA. ${ }^{10}$ Our present study confirms that IAEs remain a contributor to mortality-12\% for those who experienced an IAE compared with an overall mortality of $4.5 \%$. Occurrence of an intraoperative event and more than one occurrence were among the strongest risk factors for poor outcome. Numbers were small, but there was no association between IAE malignancy and structure injured, timing, or preventive strategic lapse.

Rescue and FaILURE To Rescue. The finding that patients with IAEs had worse-than-expected outcome helps differentiate operative and human factors from patient-dependent factors. de Leval and colleagues ${ }^{7}$ concluded that a surgeon's ability to compensate for major events was a marker of excellence (surgeon as hero), but not all major events could be compensated for. Additional surgeon qualities marking excellence include mental resilience, flexibility, and ability to raise safety awareness and remain focused despite distractions.

Silber and colleagues ${ }^{13}$ defined "failure to rescue" after coronary artery bypass grafting as occurrence of death after a complication and suggested that rescue was a measure of quality. Although in our study there was a doubling of expected poor outcomes in patients experiencing IAEs, this contribution represents only $0.65 \%$ of the total population of reoperations, corresponding to about $10 \%$ of the poor outcomes after cardiac reoperations, a relatively low figure.
Nonetheless, several events could have been prevented and others better compensated for.

Cost. Because of the association of IAEs with worse outcomes, it is no surprise that both unadjusted and adjusted costs were also greater. ${ }^{14}$ Most of these costs are related to the compensatory measures directed at rescuing these patients in the postoperative period.

\section{Validation of Reporting}

Frequency and characteristics of IAEs in the validation cohort were very similar to the study cohort. This suggests honesty of reporting. The high and fairly equal relative malignancy of different events validates our categorization and inclusion criteria.

\section{Limitations}

This study was retrospective; all IAEs were recognized and recorded by the surgeon. Using de Leval and Reasons's criteria, IAEs recorded in this study are all major (life-threatening) events. Minor events and distractions with potential to erode coping mechanisms were not recorded. It has been shown that surgeon-perceived events and errors might be inconsistent with findings of an independent observer. ${ }^{7,15}$

Lapses were recorded only for patients experiencing IAEs. Future prospective collection of more data may allow better identification of specific risks for injury, improvements in their management, and further refinement of our standardized approach for subgroups undergoing difficult reoperations.

\section{Recommendations}

Safe performance of reoperations requires a well-trained and focused team, and distractions should be minimized. Wellestablished protocols to prevent and compensate for IAEs during reoperative cardiac surgery (Appendix E3) should be universally practiced. Preoperative debriefing sessions of the complete operative team, led by the staff surgeon, may improve safety. ${ }^{16}$

\section{References}

1. Davierwala PM, Maganti M, Yau TM. Decreasing significance of left ventricular dysfunction and reoperative surgery in predicting coronary artery bypass grafting-associated mortality: a twelve-year study. J Thorac Cardiovasc Surg. 2003;126:1335-44.

2. Sabik JF 3rd, Blackstone EH, Houghtaling PL, Walts PA, Lytle BW. Is reoperation still a risk factor in coronary artery bypass surgery? Ann Thorac Surg. 2005;80:1719-27.

3. Breiman L. Bagging predictors. Machine Learning. 1996;24:123-40.

4. Blackstone EH. Breaking down barriers: helpful breakthrough statistical methods you need to understand better. J Thorac Cardiovasc Surg. 2001;122:430-9.

5. Rosenbaum PR, Rubin DB. The central role of the propensity score in observational studies for causal effects. Biometrika. 1983;70:41-55.

6. Blackstone EH. Comparing apples and oranges. J Thorac Cardiovasc Surg. 2002;123:8-15.

7. de Leval MR, Carthey J, Wright DJ, Farewell VT, Reason JT. Human factors and cardiac surgery: a multicenter study. J Thorac Cardiovasc Surg. 2000;119:661-72.

8. Reason J. Human error. Cambridge: Cambridge University Press; 1999. 
9. Follis FM, Pett SB Jr, Miller KB, Wong RS, Temes RT, Wernly JA. Catastrophic hemorrhage on sternal reentry: still a dreaded complication? Ann Thorac Surg. 1999;68:2215-9.

10. Gillinov AM, Casselman FP, Lytle BW, Blackstone EH, Parsons EM, Loop FD, et al. Injury to a patent left internal thoracic artery graft at coronary reoperation. Ann Thorac Surg. 1999;67:382-6.

11. Morishita K, Kawaharada N, Fukada J, Yamada A, Masaru T, Kuwaki K, et al. Three or more median sternotomies for patients with valve disease: role of computed tomography. Ann Thorac Surg. 2003; 75:1476-80; discussion 81.

12. Dobell AR, Jain AK. Catastrophic hemorrhage during redo sternotomy. Ann Thorac Surg. 1984;37:273-8.

13. Silber JH, Williams SV, Krakauer H, Schwartz JS. Hospital and patient characteristics associated with death after surgery. A study of adverse occurrence and failure to rescue. Med Care. 1992;30:615-29.

14. Dimick JB, Weeks WB, Karia RJ, Das S, Campbell DA Jr. Who pays for poor surgical quality? Building a business case for quality improvement. J Am Coll Surg. 2006;202:933-7.

15. Brennan TA, Gawande A, Thomas E, Studdert D. Accidental deaths, saved lives, and improved quality. N Engl J Med. 2005;353:1405-9.

16. Makary MA, Mukherjee A, Sexton JB, Syin D, Goodrich E, Hartmann E, et al. Operating room briefings and wrong-site surgery. J Am Coll Surg. 2007;204:236-43

\section{Discussion}

Dr Irving Kron (Charlottesville, $\mathrm{Va}$ ). Reoperative surgery is a common procedure, and clearly, cardiac injury is to be both anticipated and dealt with. The focus of the Cleveland Clinic manuscript is in prevention. We found it interesting that patients with a lapse in preventative strategies were more likely to be rescued than those without. We too have looked at this issue. Nine percent of our patients had an injury sustained during reoperation, though we found no significant difference in outcome with injury and without. I believe this relates to being able to institute bypass nearly immediately even when injury is suspected. I have a couple of questions for you.

When is CPB instituted before redo sternotomy? I am sure you plan this in certain situations. Second, is the ITA when patent always dissected out before performing valve surgery? We have looked at this and had found previously we occasionally injure this vessel and do not dissect it unless we need to. The final question is whether the first operation always sets up the second. Is there less injury when you are doing your own redos than those that are referred long distance?

Dr Roselli. Thanks, Dr Kron, for those excellent questions. We selectively will expose the groin or use the extrathoracic cannulation sites and rarely will use CPB before opening the chest. Our belief is that the cost you pay by early heparinization and longer CPB times is probably not worth the benefit in most cases. However, on patients who have a pseudoaneurysm or very large adherent aneurysm that we are certain we are going to get into when we open the chest, we will routinely use CPB and deep hypothermic circulatory arrest to open. I must add that in that group of patients, we have treated about 6 with custom-made stent grafts, and so we might not have to use CPB at all in some of those patients in the future.

With regard to controlling the ITA, we still do that most of the time, and when we looked at clamping of a patent ITA as a potential risk factor for injury or poor outcome, we found no correlation. I think that we just have a great team that is very good at handling that difficult dissection or determining when it is too difficult to dissect. However, when the patent ITA does become an issue, we will use some techniques that I am sure you are familiar with: cooling the patient or directly cannulating in the left main trunk and running continuous cardioplegia.

With regard to the question about whether my own redos have less of a problem, I have not had to reoperate on any of my patients yet.

Dr Kron. You will. [Laughter.]

Dr Roselli. I know I will. but certainly the patients that I have seen that did have their previous operations at the Cleveland Clinic their internal thoracic artery was in the left chest, they don't have a bypass graft that is draped across the right ventricle, and these potential pitfalls probably are less of an issue, although we didn't look at those data directly. 


\section{APPENDIX E1: Additional perioperative details collected}

History of chest radiation and indication

Preoperative CT or chest MRI

Arteriosclerotic vein grafts

ITA information: patency, midline course, fixed or mobile on cardiac catheterization

Pre-emptive groin exposure

Cannulation, CPB, and/or cooling before opening

Emergency cannulation

Arterial cannulation site(s): aorta, axillary, femoral, other

Venous cannulation site(s): right atrium, superior vena cava, inferior vena cava, femoral

Circulatory arrest

Sternal wires left in or out

Retrograde cardioplegia

Thoracotomy

Changes in original surgical plan: chest left open at completion, additional revascularization performed

Completeness of revascularization

Aorta replacement

Off-pump

Omission of procedure (eg, maze, coronary artery bypass grafting, valve replacement)

Multiple pump runs, number

Primary repair and/or graft repair of injury 
APPENDIX E2: Categorization of lapses of preventive strategies

Adverse Event (If...)

(... and) Condition

(..., then) Category

Injury on opening

No CT/MRI

$\mathrm{CT} / \mathrm{MRI}$, but no groin exposure

I

CT/MRI, but sternal wires pulled

CS

Injury to ITA
No CT/MRI
ITA "stuck" on cath film
Crossed midline, but no groin exposure
Additional revascularization, without conduit mapping

Injury to SVG or native coronary

No CT/MRI

Additional revascularization, without conduit mapping

Injury to pulmonary artery or aorta

Before CPB

CS

Injury to right atrium

Injury to brachiocephalic

No extrathoracic cannulation

CS

No CT/MRI
No axillary artery cannulation

I

Extensive lung injury

No CT/MRI

CS

Other surgeon-described technical failures

cath, Cardiac catheterization; $C P B$, cardiopulmonary bypass; $C S$, circulatory support; $C T$, computed tomography; $l$, imaging; $M R I$, magnetic resonance imaging; $T$, technical. 


\section{APPENDIX E3: Reoperative strategies and surgical techniques}

The following strategies are commonly practiced at our institution.

\section{Preoperative Evaluation}

Successful cardiac reoperations begin in the preoperative planning phase, during which the focus is directed at understanding anatomy and morphology to prevent IAEs and development of rescue plans should injury occur.

Timing of a reoperation. Consideration should be given to the fact that adhesions becomes less inflammatory and less vascularized over time; the longer the interval between operations the better. Reoperation between 3 weeks and 6 months from the last operation is the most difficult. Previous radiation alters the healing process, and maturation of adhesions slows down such that they often remain fleshy even after several years, making identification of the dissection plane and reoperations difficult in this setting.

Imaging studies. Performance of the appropriate imaging studies is not a guarantee of their utility. Surgeons should be adept at interpreting the studies, including cardiac catheterization films, CT, and MRI. The following studies should be performed with techniques as described. Chest radiograph should be performed with anteroposterior and lateral views in all patients. CT or MRI should be enhanced by 3 -dimensional reconstructions and by contrast if necessary to visualize coronary arteries or grafts. Gated studies improve clarity and provide further details regarding patency of coronaries and grafts. These examinations will disclose the anatomic relations and condition of the aorta. Arterial pseudoaneurysms are particularly important to characterize because they are often in close proximity to the sternum. Cardiac catheterization should be performed for all patients who have had previous coronary artery bypass grafting. Coronaries and grafts normally move with the heart during the cardiac cycle, but if segments are immobile, that means they are restricted by dense scar tissue. Peeling them off the anterior chest wall is challenging, requiring manipulation, and risk of injury is high. Patent ITAs are particularly valuable and vulnerable, and a patent ITA crossing the midline adds to the challenge. For each previous bypass graft, its importance to myocardial perfusion, risk for sustaining injury, and a rescue plan should injury occur must be understood as part of the planning process. Knowing availability of conduits for replacement or additional coronary artery bypass grafts is necessary in case of known or suspected coronary disease. Ultrasonographic mapping is a valuable technique to assess availability of conduits, but is not reliable.

Additional considerations when reviewing imaging studies include evaluation of patency and morphology of axillary, iliac, and femoral vessels should the need for extrathoracic cannulation arise (see below). One should also be wary of innominate artery stenosis if axillary cannulation is contemplated, and aberrant right subclavian arteries, thoracoabdominal aortic aneurysms, aortoiliac occlusive disease, and inferior vena cava filters in preparation for planning alternate (including guidewire-dependent) cannulation strategies.

\section{Surgical Plan}

Successfully preventing and compensating for IAEs depends on optimal preparedness for potential injuries during each phase of the operation and executing well-coordinated rescue strategies as the operation develops. The operating room team should be briefed on the surgical plan, including structures at risk and expected action should a particular injury occur. The team must be prepared and the tools readily available for immediate execution of any rescue plan. In the text that follows, potential injuries, preventive strategies used to avoid them, and rescue strategies used to compensate for them should be discussed for each phase of the operation:

\section{Sternal Reentry}

Before sawing the sternum, the surgeon should open the epigastric fascia and dissect the inferior heart away from the chest wall. An oscillating saw should be used while the assistant provides anteriorly directed traction on the sternum, leaving the posterior periosteum intact to be sharply cut with scalpel or scissors. Sternal wires can be left in while opening the posterior table to protect structures that are closely adherent to the sternum.

Estimated risk of sternal reentry is based on known cardiac disease, previous operation(s), and interpretation of preoperative imaging studies. Optimal preparedness includes selective exposure of alternative cannulation sites, because prompt institution of $\mathrm{CPB}$ minimizes danger of adverse events.

Venous structures at risk during sternal reentry include the innominate vein, right atrium, and right ventricle. Patients with right heart failure are especially at risk. When a venous structure is injured, any arterial or venous access is useful for retransfusion, although arterial is optimal. The right axillary artery has become our preferred alternative site for arterial access, and is routinely used in cases with severe ascending aorta atherosclerosis. Axillary arteries are less likely to be severely atherosclerotic than the femoral arteries, and reversed flow in the descending aorta from femoral cannulation increases risk of stroke in a severely atherosclerotic aorta and risk of aortic rupture and malperfusion in aortic dissection.

Arterial injury is immediately life threatening and requires both arterial and venous exposure. In a crisis, any access is useful for retransfusion for maintaining circulatory volume until arterial access has been obtained. Again, we prefer axillary artery cannulation, but if it is not anticipated and time is an issue, cannulating the femoral artery is expedient. In such situations, we convert to arterial inflow to the aorta once it is feasible to provide antegrade flow. Knowing the condition of the femoral artery beforehand is important because time is of the essence during rescue, and femoral arteries are commonly severely calcified or even occluded and impossible to use.

Situations that are particularly high risk for arterial injury include aortic aneurysms or pseudoaneurysms adherent to the sternum or important bypass grafts crossing the midline that are fixed to the sternum. In these situations, some surgeons carry the initial dissection high up under the sternum before sawing, but risk for injury to the graft cannot be eliminated with this technique. In these cases, we believe it is justified to cannulate and establish CPB with or without hypothermic circulatory arrest before opening the sternum. However, CPB before sternotomy or dissection is used only selectively because of consequent bleeding, prolonged $\mathrm{CPB}$, and excessive cardiotomy suction.

Avoiding sternotomy is seldom but occasionally an option. Mitral or tricuspid valve operations can be performed via right thoracotomy without aortic clamping, but in our experience this approach has been used only selectively because of an associated increased risk of stroke. Coronary arteries can also be approached via 
minithoracotomy without $\mathrm{CPB}$ or by a hybrid procedure in combination with percutaneous intervention.

\section{Dissection}

Once the sternum is divided, the right sternal border is released from the heart. Too much traction can tear the right ventricle or right atrium. Beware of right heart failure with associated dilated atrium and ventricle! To avoid injuring these structures, the surgeon should start the dissection laterally and should carry it medially, often opening the right pleura if necessary. Dissection plane should be close to the chest wall, but sparing of the right ITA. During dissection, cautery should be limited, and sternal traction should be gentle and upward. Advantage should be taken of any clearly identifiable proper dissection plane, and once it is identified, one should stay in it. Usually, the correct plane can be developed along the diaphragmatic surface, then up around the right atrium toward the aorta. A "no-touch" technique should be applied to patent vein grafts by dissecting away from the grafts. Dissection on the aorta should proceed slowly and diligently to avoid entering and extending beneath the adventitia. At this point, standard aortic and atrial or bicaval cannulation is usually possible and marks an important stage in the dissection process. If grafts embedded in scar tissue are encountered while performing the aortic dissection, extrathoracic arterial cannulation is an excellent alternative, preferably using the axillary artery. Only then is attention directed toward the left sternal border. This may be released by staying close to the chest wall. One should beware of the position of a patent ITA. Once the pericardial reflection is identified, further dissection in the correct plane is facilitated. Lifting the pericardial border stretches the adhesions, improves exposure, and opens the plane of dissection. Cutting with scissors should be synchronous with heart rhythm. If the dissection has been carried this far before giving heparin, one has done as much as is necessary off-pump, and cannulation should be commenced. Alternatively, if the dissection planes open up nicely, it is reasonable to continue along the pericardial border to the level of the patent ITA. Similarly, the space lateral to the aorta and above the pulmonary artery may be exposed to allow safe aortic clamping, but only if this plane develops easily. Dissection of the left heart should be completed on CPB, preferably with the heart arrested. The heart should not be dissected more than needed to safely perform the planned operation.

\section{Operative Considerations}

A detailed discussion of pathology-specific operative strategies goes beyond the scope of this article, but particular details about the con- duct of operations warrant mention. Myocardial protection requires increased diligence during reoperations because reoperations are longer, coronary disease more advanced, and function often worse than in primary procedures. Our routine is to use antegrade induction and place the retrograde cardioplegia cannula in the coronary sinus. We have a low threshold to place this cannula directly to optimize delivery and protection of the right ventricle. Retrograde cardioplegia is particularly important when the patient has patent old vein grafts, because of risk of embolization. If a patent ITA graft cannot be exposed and controlled, our preference is to combine moderate systemic cooling with continuous slow infusion of cold cardioplegia directly into the left coronary ostium.

Multicomponent, complex procedures are more likely during reoperations and are generally performed in the order maze/pulmonary vein isolation, bypass grafts, mitral valve, aortic valve, pulmonary valve, and tricuspid valve followed by closing all incisions in the heart and performing proximal anastomoses to the aorta. Performing an atrial fibrillation ablation procedure may require risky additional dissection, and patients should be informed that it may be abandoned if conditions are unfavorable. Bypass grafts should be performed early to optimize myocardial protection.

\section{Rescue Strategies (Additional Comments)}

Once injury or ischemia occurs, prime objectives are to protect the brain and heart. This often requires emergency cannulation and hypothermia with or without circulatory arrest. Perfusion or cardioplegia to the injured cardiac territory should be optimized by primary repair of injuries, retrograde delivery of cardioplegic solution via the coronary sinus, and control of a patent ITA graft. While the aorta is clamped, cardioplegic solution should be given down new vein grafts, especially to poorly collateralized areas, and all attempts should be made to fully revascularize all territories. Primary repair of injured bypass grafts should be backed up with a replacement graft.

When faced with an adverse event, the benefit of additional procedures such as ablation of atrial fibrillation, bypass grafting of a moderately diseased vessel amenable to later percutaneous intervention, or incidental replacement of an old tissue valve may need to be reconsidered. Rarely, when the pre-pump dissection has been associated with excessive bleeding from multiple superficial injuries and coagulopathy, a patient may require resuscitation in the intensive care unit before returning to the operating room to complete the operation. Finally, return to CPB should never be delayed to facilitate repair of severe injuries. 


\section{APPENDIX E4: Variables considered in multivariable analyses of intraoperative adverse events and poor outcomes \\ Demographics}

Age, sex, height, weight, body surface area, body mass index

\section{Preoperative Status}

New York Heart Association functional class, Canadian Angina Class, emergency operation

\section{Cardiac Comorbidity}

Preoperative atrial fibrillation, number of coronary systems with $50 \%$ stenosis or more, $50 \%$ or more stenosis of left anterior descending coronary artery, left main trunk, right coronary artery, or left circumflex coronary artery, family history of coronary artery disease, ventricular arrhythmia, complete heart block, history of endocarditis, history of heart failure, left ventricular function, left ventricular ejection fraction, previous myocardial infarction, degree of valve regurgitation and stenosis (aortic, mitral, tricuspid), carotid disease, status of aorta (calcified, dilated, aneurysmal, arteriosclerotic), number of previous cardiac operations, and time from last cardiac operation

\section{Noncardiac Comorbidity}

History of hypertension, history of treated diabetes (insulin-/noninsulin-dependent), previous stroke, smoking history, peripheral arterial disease, chronic obstructive pulmonary disease, renal failure, blood urea nitrogen, creatinine, bilirubin, cholesterol (total, high-density lipoprotein, low-density lipoprotein), triglycerides, hematocrit, previous chest radiation, cancer, and liver failure

\section{Prior Operations}

Previous aortic, mitral, or tricuspid valve repair or replacement, coronary artery bypass grafting, use of ITA graft, thoracic aorta repair, and place of previous operation

\section{Experience \\ Surgeon}

\section{Additional Variables Examined for Poor Outcome}

Cannulation site (arterial: aorta, femoral artery, axillary artery; venous: right atrium, vena cava, femoral vein), procedure (aortic, mitral, or tricuspid valve repair or replacement, coronary artery bypass grafting, use of ITA graft, number of ITA grafts, aortic valve allograft replacement), intraoperative adverse event (yes/no, number) 
APPENDIX E5: Incremental risk factors for poor outcomes (stroke, myocardial infarction, hospital death) in patients who did not experience IAEs $(\mathbf{n}=1720)$. This model was used to calculate failure to rescue

\begin{tabular}{|c|c|c|c|c|}
\hline Variable & Estimate $\pm S E$ & $P$ value & Reliability $(\%)^{*}$ & $P$ in IAE group $\dagger$ \\
\hline \multicolumn{5}{|l|}{ Prior operation } \\
\hline Prior CABG & $0.62 \pm 0.26$ & .01 & 60 & .4 \\
\hline Prior TV surgery & $0.94 \pm 0.43$ & .03 & 53 & .9 \\
\hline \multicolumn{5}{|l|}{ Noncardiac comorbidity } \\
\hline Higher preoperative bilirubin $\ddagger$ & $0.46 \pm 0.17$ & .007 & 87 & .9 \\
\hline Higher preoperative creatinine $\ddagger$ & $0.58 \pm 0.21$ & .007 & 51 & .9 \\
\hline History of carotid disease & $0.63 \pm 0.24$ & .008 & 50 & .7 \\
\hline \multicolumn{5}{|l|}{ Cardiac morbidity } \\
\hline More severe TV regurgitation & $0.40 \pm 0.08$ & $<.0001$ & 85 & .5 \\
\hline \multicolumn{5}{|l|}{ Reoperation procedure } \\
\hline Femoral arterial cannulation & $1.01 \pm 0.50$ & .04 & 60 & 6 \\
\hline Aortic arterial cannulation (less) & $-0.65 \pm 0.26$ & .01 & 45 & .8 \\
\hline AV allograft replacement & $0.94 \pm 0.37$ & .01 & 50 & .7 \\
\hline Intercept & $-3.8 \pm 0.37$ & $<.0001$ & - & - \\
\hline
\end{tabular}

